\title{
Everyday DiscriminATION In CANADA: Prevalence ANd Patterns
}

\author{
JENNy GodLey
}

\begin{abstract}
Using nationally representative data from the 2013 Canadian Community Health Survey, this article examines the prevalence and patterning of self-reported everyday discrimination in Canada. Almost twenty-three percent of Canadians report experiencing everyday discrimination. The most common types reported are gender, age, and race, followed by discrimination based on physical characteristics such as weight. Sex, age, marital status, race, place of birth, and body mass index all contribute to individuals' reported experiences of discrimination. Gay men report particularly high levels of discrimination based on sexual orientation; Blacks, Asians, and Aboriginals report particularly high levels of racial discrimination; and Arabs, South and West Asians, and Aboriginals report particularly high levels of religious discrimination. There is strong evidence of the persistence of everyday discrimination in Canada, across multiple social groups, despite legal protections for marginalized groups. Suggestions are made for addressing the roots of discrimination at both the individual and the collective levels.
\end{abstract}

Keywords: Everyday Discrimination; Canada; Racism; Sexism; Weight Bias

Résumé. Utilisant les données nationales de l'enquête de 2013 sur la santé dans les collectivités canadiennes, cet article examine la prévalence et les profils de la discrimination quotidienne auto déclarée au Canada. Près de vingt-trois pourcent des Canadiens disent subir de la discrimination au quotidien. Les cas les plus courants sont ceux liée au genre, à l'âge et à la race. Vient ensuite la discrimination basée sur les caractéristiques physiques telles que le poids. Ainsi, le sexe, l'âge, le statut matrimonial, la race, le lieu de naissance et l'indice de masse corporelle contribuent-ils tous aux expériences discriminatoires rapportées par les individus. Les hommes gay rapportent des niveaux particulièrement élevés de discrimination basée sur l'orientation sexuelle. Les Noirs, les Asiatiques et les Autochtones signalent des niveaux particulièrement élevés de discrimination raciale. Pour leur part, les Arabes, les ressortissants d'Asie du Sud et de l'Ouest, ainsi que les Aborigènes font état de niveaux particulièrement élevés de discrimination religieuse. En dépit de dispositions légales pour protéger les groupes marginalisés, persistent au Canada, de solides preuves de discriminations à travers plusieurs groupes sociaux. Quelques suggestions sont formulées dans le but de s'attaquer aux racines de la discrimination aux niveaux aussi bien individuel que collectif.

Mots clés: La discrimination quotidienne; Canada; Racisme; Sexisme; Biais de poids 


\section{INTRODUCTION}

nternationally, Canada has a reputation as a multicultural haven, where social inequality is low, difference is welcomed, and government programmes work to create a more egalitarian society (Jedwab 2014; Kymlicka 2004; Siddiqi et al. 2013). Since the election of Donald J. Trump as president of the United States, journalists and academics alike have been comparing new restrictive US policies on immigration and health care to more liberal Canadian policies, arguing that Canada is a more tolerant society (Giroux 2017). At the same time, ongoing patterns of prejudice such as sexual harassment, racial discrimination, and bias against Aboriginals have been making the headlines throughout North America, as social movements such as \#MeToo and Black Lives Matter gain momentum and media coverage (Austen \& Porter 2018).

Canadian sociologists have a long history of questioning the idealistic view of Canadian society as egalitarian by providing evidence of ongoing structural inequalities. In the mid-1960's, sociologist John Porter provided empirical evidence to refute the myth of Canada as a classless society in his seminal work, The Vertical Mosaic. Porter argued that class inequality in Canada had in fact increased over the first part of the twentieth century. He demonstrated that education and income were unequally distributed, and that ethnicity and immigration contributed heavily to this unequal distribution (Porter 1965).

In the introduction to the $50^{\text {th }}$ Anniversary edition of The Vertical Mosaic, printed in 2015, Jedwab and Satzewich claim that inequality has continued to increase in Canada during the second half of the twentieth century. They propose that such inequality must be understood as multi-faceted; the intersecting axes of gender, race / ethnicity, immigrant status, and social class all contribute to pervasive structural inequality in Canadian society. Crediting Porter for initiating the study of inequality and discrimination in Canadian sociology, they argue that there is much work still to be done (Jedwab \& Satzewich 2015: xxix).

Researchers following Porter's lead have demonstrated that gender, race, ethnicity, immigration status, physical appearance, weight, and sexual identity are all related to Canadians' access to and accumulation of education and income, and to their health and life expectancy (Abada et al. 2009; Guppy \& Luongo 2015; Lightman \& Gingrich 2012; Ramraj et al. 2016). Importantly, sociologists have argued that different forms of discrimination, including racism, sexism, and ageism, all contribute to ongoing social inequalities in Canadian society (Browne 2017; Fleras 2014; Jedwab 2014; Nagra \& Maurutto 2016). 
Discrimination is defined as negative or unfair treatment of individuals based on their membership in a specific marginalized social group (or in multiple marginalized social groups) (Onufrio 2013). Sociologists have derived various measures of discrimination, both from the perspective of the perpetrator (measures of prejudice or bias) and from the perspective of the victim (experiences of discriminatory events or incidents) (Samuel \& Verma 2010). Surveys assessing respondents' perceptions of discrimination are generally accepted as the most inclusive way to measure discrimination (Galabuzi 2010). However, sociologists also recognize that self-reports are not unbiased; a multitude of factors will influence whether individuals regard themselves as victims of discrimination at any particular point in time, including the current social and political climate (Kaiser \& Major 2006).

Recent media reports have highlighted the rise of different types and experiences of discrimination in Canada. Hate crime statistics are one (some argue, the most severe) indicator of the prevalence of discrimination. Data from Statistics Canada show that hate crimes against Muslims in Canada rose 61\% from 2014 to 2015, suggesting that severe instances of discrimination against certain groups in Canada are increasing (Leber 2017). Meanwhile, other reports suggest that Canadians from marginalized groups also experience more subtle forms of discrimination on a daily basis. A recent poll conducted following the rise of the \#MeToo movement found that over $50 \%$ of Canadian adult women reported experiencing unwanted sexual pressure at work, with one out of ten women saying that sexual harassment is 'quite common' in their workplace (Anderson 2017).

There is little consistent academic data on the prevalence of different kinds of discrimination in Canada. Discrimination also occurs for reasons other than race, religion, or gender, and can occur in a variety of settings. Yet quantitative empirical work documenting the overall prevalence and patterning of experiences of different types of discrimination in Canada is scant. This article uses nationally representative survey data from 2013 (before the more recent rise of the new social movements such as \#MeToo and Black Lives Matter) to assess the extent to which Canadians reported experiencing routine acts of discrimination because of their membership in various marginalized groups.

\section{Literature REVIEW}

Human rights legislation emerged in the 1960s and 70s in Canada, with the 1982 Charter of Rights and Freedoms establishing anti-discrimina- 
tion laws both federally and provincially. The Canadian Human Rights Commission is charged with implementing the anti-discrimination legislation, which prohibits discrimination based on thirteen grounds: race; national or ethnic origin; colour; religion; age; sex; sexual orientation; gender identity or expression; marital status; family status; genetic characteristics; disability; and a conviction for which a pardon has been granted or a record suspended (http://www.chrc-ccdp.gc.ca/index.html). This list of grounds for discrimination is not static, as is evidenced by the fact that genetic characteristics were added as ground for discrimination in 2016. Although these laws only apply to federally regulated employers and service providers, each province also has its own laws, most of which follow the federal laws fairly closely.

One way to measure the prevalence of discrimination in Canada, therefore, would be to examine legal data such as the number and types of hate crimes or instances of hate speech reported, or the number and types of Human Rights cases filed at the national or provincial level. However, sociologists have long argued that such measures only capture the most severe forms of discrimination (and may only capture those who have the resources to pursue legal action), and not the subtler forms of discrimination that members of marginalized groups may encounter on a regular basis (Driedger \& Mezoff 1981; Samuel \& Verma 2010).

Quantitative sociologists have developed several ways to measure individuals' experiences with discrimination using survey techniques. One measure focuses on what are called 'major incidents of discrimination' (Williams et al. 2012). Respondents are asked to report if they have ever experienced things such as being denied employment or promotion, being fired, being denied housing, being denied a bank loan, or even things as serious as being stopped by the police or being a victim of a hate crime because of their social status (Williams 2016). Most of the research using this "major incidents" measure is US based and focuses on discrimination due to sex or race (Pager \& Shepherd 2008).

The Everyday Discrimination Scale (EDS), originally developed for use in health research (Williams et al. 1997), captures self reports of subtler, yet also potentially much more frequent, interpersonal forms of discrimination. In an attempt to understand the pathways through which race affects health in the United States, Williams and colleagues developed a self-reported measure of chronic, repeat experiences with discrimination that occur in daily interpersonal social interactions. These experiences include events that are sometimes referred to as "microaggressions" or "microinsults," where individuals encounter clear examples of unfair treatment and disrespect due to their social status (Fleras 2016). 
The scale as originally developed by Williams and colleagues was a nine-item instrument, asking respondents, "In your day-to-day life, how often do any of the following things happen to you? You are treated with less courtesy than other people are; you are treated with less respect than other people are; you receive poorer service than other people at restaurants or stores; people act as if they think you are not smart; people act as if they are afraid of you; people act as if they think you are dishonest; people act as if they're better than you are; you are called names or insulted; you are threatened or harassed." For each of the nine items, respondents could choose from the following responses: "At least once a week; a few times a month; a few times a year; less than once a year; never."

If a respondent indicated that they had experienced at least one of these events, the following follow up question was asked: "What do you think the reasons might be for you to have had these experiences?" Depending on the survey, a list of responses then followed, with respondents able to choose multiple responses. The response lists included such items as: "ancestry or national origins; gender; race; age; religion; height; weight; another aspect of physical appearance; sexual orientation; education or income; physical disability; shade of skin color." The response list varies over time and across studies, making it difficult to compare results, but most versions include at least gender, race, age, and physical disability. If respondents chose more than one reason for discrimination, they were then asked, "What do you think was the main reason," to which they could give only one answer.

Versions of the EDS have been used in hundreds of studies since the late 1990s, mostly in the public health and biomedical literature (Williams \& Mohammed 2013). The original scale has been modified several times, both in terms of the number of items used and in terms of the list of possible reasons for discrimination (Kim et al. 2014). The version of the scale used in this research (described more completely in the methods section, below) is the revised five-item EDS, developed and validated in 2011 (Stucky et al. 2011).

Because the EDS is a self-reported measure, it is important to acknowledge that it may suffer from two, potentially contradictory, biases. Some types of people may under-report discriminatory experiences (a minimization bias), due to shame, a lack of awareness, fear of repercussions, or other individual-level factors. At the same time, other types of people may over-report such experiences (a vigilance bias), due to depression, stress, a heightened focus on their marginalized status, or other individual-level factors (Satzewich 2010). There is no conclusive evidence that either of these biases dominates, but we must keep them both 
in mind when analyzing data from the EDS (Kaiser \& Major 2006). We must also keep in mind that self-reports captured by the EDS may well be affected by cultural and historical factors (such as the rise of certain social movements) that heighten awareness of (and, perhaps, willingness to report on) certain types of discrimination.

Over the past twenty years, researchers using different versions of the EDS have demonstrated conclusively that respondents experience a variety of forms of discrimination, and that there are negative physical and mental health effects of routine self-reported experiences of discrimination (for two recent reviews of this research see Pascoe \& Richman 2009 and Lewis et al. 2015). Most of these studies have been conducted in the United States, and most have focused on discrimination due to race or ethnicity (Williams \& Mohammed 2009, 2013). Research using self-reports of discrimination in Canada has also shown that Aboriginal people and ethnic and racial minorities face discrimination, and that discrimination can be detrimental to health (Beiser \& Hou 2016; Browne 2017; Kim \& Noh 2016; Nakhaie \& Wijesingha 2015; Spence et al. 2016). Perceived discrimination may affect health through multiple direct and indirect pathways, including distrust in the healthcare system, increases in risky health behaviours, and decreases in social capital (Chen \& Yang 2014; Lewis et al. 2015; Pascoe \& Smart 2009).

To the author's knowledge, before 2013 there had been only two nationally representative Canadian surveys that measured self-reported experiences of discrimination: the Ethnic Diversity Survey (EDS) and the General Social Survey (GSS). The EDS (2002) includes one question to assess respondents' experiences of discrimination, "(Over the past five years) do you feel that you have experienced discrimination or been treated unfairly by others in Canada because of your ethnicity, race, skin colour, language, accent, or religion?" (Galabuzi 2010). Results from this survey showed that $20 \%$ of visible minority respondents reported experiencing this type of discrimination "sometimes or often", and 5\% of non-visible minority respondents reported experiencing this type of discrimination "sometimes or often" over the past five years (Satzewich 2010).

The 2004, 2009, and 2013 GSS asked questions regarding respondents' experiences of discrimination for several different reasons: "In the past five years have you experienced discrimination or been treated unfairly by others in Canada because of: your ethnicity or culture; your race or colour; your religion; language; sex; sexual orientation; age; disability; other; or physical appearance other than skin colour (added in the 2009 version)." Nakhaie and Wijesingha used the 2004 GSS data to examine the effects of discrimination on the self-rated health of immi- 
grants in Canada. They found that the effect of perceived discrimination on self-rated health was stronger for female immigrants than for male immigrants (Nakhaie \& Wijesingha 2015). Using the 2009 GSS data, DuMont and Forte found that experiences of discrimination based on physical appearance and disability have particularly negative effects on health (DuMont \& Forte 2016).

Although neither of these studies explicitly examined either the prevalence or the predictors of the different types of discrimination in Canada, focusing instead on the effects of self-reported discrimination on health, the findings reported by DuMont and Forte (2016) can be used to construct estimates of the overall prevalence of different types of self-reported discrimination in Canada. They found that approximately $15 \%$ of all Canadians reported experiencing any discrimination over the past five years. Examining the individual types of discrimination separately, they showed that approximately $5.4 \%$ of Canadians reported experiencing discrimination due to ethnicity or culture, $5.1 \%$ due to race or colour, $4.7 \%$ due to sex, $3.9 \%$ due to physical appearance (other than skin colour), $3.3 \%$ due to age, $3 \%$ due to language, $2.5 \%$ due to religion, $1.1 \%$ due to disability, and $1 \%$ due to sexual orientation (DuMont \& Forte 2016).

In 2013, the Public Health Agency of Canada added a version of the EDS as a Rapid Response Module to the Canadian Community Health Survey, with the following objective: “...to support better research and interventions on the links between discrimination and key health and social outcomes." (Statistics Canada 2016a). In this article, I use this new, nationally representative data to examine the prevalence and patterning of experiences of everyday discrimination among Canadians, focusing on the following research questions:

1. What is the current prevalence of different types of self-reported everyday discrimination in Canada?

2. Who is most likely to report having experienced each of the different types of everyday discrimination?

\section{Data ANd Methods}

The Canadian Community Health Survey (CCHS) is a nationally representative, cross-sectional survey conducted by Statistics Canada. The CCHS was conducted biannually from 2001 to 2005 and has been conducted annually since 2007. The survey contains questions about the determinants of health, health outcomes, health behaviours, and health care utilization. The target population is all residents of Canada who 
are at least twelve years old in the ten provinces and the three territories, excluding individuals living on Indian Reserves or other Aboriginal settlements, institutional residents, full-time members of the Canadian Armed Forces, residents of some remote regions, and those living in two Quebec health regions - Région du Nunavik and Région des TerresCries-de-la-Baie-James. (These exclusions represent less than 3\% of the Canadian population) (Statistics Canada 2016b).

Data is collected for the CCHS on an ongoing basis throughout the year. The Rapid Response Module (RRM) is conducted during the summer months and excludes residents of the three Territories. The 2013 RRM data were collected from July through October 2013 and were available to researchers in 2016 (Statistics Canada 2016a). The household level response rate for the 2013 RRM is $76.3 \%$ (Statistics Canada 2016b).

\section{Sample, data analysis, and weighting}

The original sample for the 2013 RRM of the CCHS is approximately 19,000 individuals. In this article, the sample is restricted to those age 25 or above who answered the Everyday Discrimination Scale, approximately 16,000 individuals. I chose to restrict the analyses to those aged 25 and above so that the education variable represents (in most cases) completed education. For the multivariate models, individuals with missing data on any independent variable are removed from the sample, resulting in a sample size of approximately $15,000^{1}$. Information regarding the number of people missing on each of the independent variables is provided in the measures section, below. It should be noted that the 2013 RRM of the CCHS can only be used to make national estimates, as the sample size is too small to look at smaller geographic units. Therefore, all results are presented at the national level.

The data were accessed and analyzed using STATA Version 14 in the Prairie Regional Research Data Centre. All results presented in this article have been vetted by Statistics Canada staff to ensure respondent confidentiality. Following Statistics Canada protocol, cell sizes less than five are not disclosed. The data are weighted to account for stratified sampling and non-response (by province, age group, and sex). The standard errors in all the regression models were estimated using the bootstrap weights provided by Statistics Canada, to account for the complex sampling design (Statistics Canada 2016d).

1. Note the sample size drops for the model of discrimination based on sexual orientation, as described below. 


\section{Measures}

The main dependent variables for this study are constructed from the revised version of the EDS contained in the CCHS RRM. This section of the survey began with the following prompt: "In the following questions, we are interested in your opinion on how often other people have treated you unfairly because of such things as your gender, race, age or appearance." It continued: "In your day-to-day life, how often do any of the following things happen to you?

1. You are treated with less courtesy or respect than other people are.

2. You receive poorer service than other people at restaurants or stores.

3. People act as if they think you are not smart.

4. People act as if they are afraid of you.

5. You are threatened or harassed."

For each of the above questions, the possible responses were: "at least once a week; a few times a month; a few times a year; less than once a year; never."

If a respondent answered anything more than "never" to any of the questions, the following question was asked: "What do you think the reasons might be for you to have had these experiences?" Responses (of which respondents could choose more than one) included: "your race; your gender; your age; your weight; your religion; your sexual orientation; a physical disability; something else related to your physical appearance; your income; a mental health issue." If respondents chose more than one reason, they were then asked the following question: "Of the reasons you just mentioned, which one do you think is the main reason?" (Statistics Canada 2016c).

Because of the way the questions were asked, it was not possible to assign individual forms of discrimination to individual reasons for discrimination. Therefore, this article focuses solely on the reasons for discrimination reported by respondents. Any respondent who reported experiencing any form of discrimination 'less than once a year' or more (as opposed to 'never') is classified as having experienced that type of discrimination. If a respondent chose more than one type, they are also classified by the 'main type' of discrimination they experienced. The distributions of these dependent variables, self-reported experiences of discrimination, are described in the results section, below.

Table 1, below, contains the distribution of the independent variables used in the multivariate models: 
Table 1: Descriptive Statistics - CCHS RRM, 2013, Respondents aged 25+

\begin{tabular}{|c|c|c|}
\hline Variable & & $\%$ missing \\
\hline Percent Female & 51.24 & None \\
\hline Mean Age & $50.66(50.45-50.86)$ & None \\
\hline \multicolumn{3}{|l|}{ Age groups } \\
\hline $25-45$ & 40.52 & \\
\hline $46-65$ & 40.13 & \\
\hline $66+$ & 19.36 & \\
\hline Marital Status & & $.097 \%$ \\
\hline Married or Common Law & 69.83 & \\
\hline Divorced or Separated & 10.07 & \\
\hline Widowed & 5.51 & \\
\hline Single & 14.59 & \\
\hline Education & & $1.84 \%$ \\
\hline Grade 8 & 5.11 & \\
\hline Grade 9 & 4.69 & \\
\hline Grade 11 & 2.95 & \\
\hline High School Graduate & 18.68 & \\
\hline Some post secondary & 4.11 & \\
\hline Trade certificate & 10.82 & \\
\hline College certificate & 22.94 & \\
\hline University Certificate & 3.15 & \\
\hline BA & 18.37 & \\
\hline More than BA & 9.18 & \\
\hline Mean Education & $6.26(6.20-6.33)$ & \\
\hline Mean Household Income & $66,212(65,218-67,206)$ & $24.82 \%$ - imputed \\
\hline Mean Household Size & $2.72(2.67-2.78)$ & None \\
\hline Mean Income adj. for HH Size & $41,883(41,255-42,510)$ & \\
\hline Race / Ethnicity & & $.66 \%$ \\
\hline White & 78.9 & \\
\hline Aboriginal & 3.03 & \\
\hline Black & 2.37 & \\
\hline Asian (incl SEAsian) & 6.93 & \\
\hline South and West Asian & 4.74 & \\
\hline Arab & 1.06 & \\
\hline Latin American & 1.00 & \\
\hline Other & .99 & \\
\hline Multiple & .97 & \\
\hline Born in Canada & $73.72 \%$ & $.89 \%$ \\
\hline BMI (mean) & $26.34(26.23-26.46)$ & $4.29 \%$ \\
\hline Sexuality - LGB* & $2.38 \%$ & $31.19 \%$ \\
\hline
\end{tabular}

Notes: Initial N = 16,049; Weighted results shown.

*Sexuality was only asked of a sub sample, those aged 18-59 
Sex and age were self-reported, and there were no missing values. In the multivariate analyses, age is collapsed into three groups to represent different cohorts: young adults (25-45, born 1968-1988); middle-aged adults (46-64, born 1949-1967); and older adults (65+, born 1948 and earlier). Marital status was coded into four categories: married or common-law; divorced or separated; widowed / widower; and single (never married). Less than $1 \%$ of the sample was missing data on marital status.

The measure of race / ethnicity was constructed by combining two questions. The first question asked: "Are you an Aboriginal person, that is, First Nations, Metis or Inuk (Inuit)? First Nations includes Status and Non-Status Indians." The second question asked: "You may belong to one or more racial or cultural groups on the following list. Are you: White, South Asian (e.g., East Indian, Pakistani, Sri Lankan etc.), Chinese, Black, Filipino, Latin American, Arab, Southeast Asian (e.g. Vietnamese, Cambodian, Malaysian, Laotian, etc.), West Asian (e.g., Iranian, Afghan, etc.), Korean, Japanese, or Other?" (Respondents could pick up to four). Anyone who answered yes to the first question was not asked the second question about racial or cultural group membership; thus, they were classified as Aboriginal. The responses to the second question were collapsed as follows: White; Black; Asian (included Chinese, Filipino, Southeast Asian, Japanese, and Korean); South and West Asian (included South Asian and West Asian); Arab; Latin American; Other and Multiple. Anyone who checked more than one response to the second question was classified as Multiple Race. Less than 1\% of respondents were missing data on race / ethnicity.

Respondents were asked to list their highest level of completed education, and a ten-level education variable was created with the following response categories: Grade 8; Grade 9; Grade 11; Secondary School (no post-secondary); Some post-secondary; Trade certificate; College Certificate: University Certificate (less than BA): BA; More than BA. Education was included in the multivariate models as a continuous variable, ranging from one (Grade 8) to ten (More than BA). Approximately 2\% of respondents had missing data on education.

Respondents were asked to report their total household income in the past twelve months. For those who did not report, income was imputed by Statistics Canada. Approximately $25 \%$ of respondents had imputed income. All multivariate models using income were also run with a dummy variable included for imputed income (results not shown). This dummy variable was not significant in any model, so income is used with imputed values included to retain sample size. As recommended by Statistics Canada, income is adjusted for household size by dividing 
total household income by the square root of household size (Chen et al. 2012).

Respondents were asked what country they were born in. This variable was dichotomized to capture those born in Canada and those born outside Canada. Less than $1 \%$ of respondents were missing information on place of birth.

BMI was calculated from respondents' self reported height and weight $\left(\mathrm{kg} / \mathrm{m}^{2}\right)$. Pregnant women do not have data on height and weight and are therefore excluded from the multivariate analysis. Some research has shown that self-reports may underestimate BMI (John et al. 2006), but others have argued that self-reported BMI is valid as long as it is used as a continuous variable (Spencer et al. 2002). To reduce the chance of errors due to self-report, BMI was standardized independently by sex, and was coded as missing for all those whose BMI was above +3.29 or below -3.29 standard deviations from the mean for their sex. Including pregnant women and those who did not respond to the height and weight questions, $4.29 \%$ of the sample missing on $\mathrm{BMI}^{2}$.

A subset of respondents, aged 18-59, were asked about their sexuality. This question was asked as follows: "Do you consider yourself to be...?" Response categories were: "heterosexual (sexual relations with people of the opposite sex); homosexual, that is lesbian or gay (sexual relations with people of your own sex); bisexual (sexual relations with people of both sexes)." Because the question was only asked of those age 18-59, approximately one third of the initial sample (those 60 and above) are missing data on sexuality. Therefore, the multivariate model of discrimination due to sexual orientation is run (and presented) separately from the other models, below.

\section{Results}

Table 2 examines the distribution of the dependent variables, self-reported experiences of different types of discrimination, to answer the first research question: What is the current prevalence of different types of everyday discrimination in Canada?

2. Analyses conducted on those with missing data on BMI showed that they were predominantly women, and that they reported significantly higher rates of weight discrimination than those who were not missing data on BMI. Thus, the results in this article regarding the prevalence of weight discrimination should be considered conservative. 
Table 2: Canadians' Experiences of Everyday Discrimination

\begin{tabular}{|c|c|c|}
\hline Discrimination Type & $\begin{array}{l}\text { Ever experienced, \% } \\
(95 \% \mathrm{Cl})\end{array}$ & $\begin{array}{l}\text { If experienced, MAIN or ONLY type, \% } \\
(95 \% \mathrm{Cl})\end{array}$ \\
\hline Any discrimination & $\begin{array}{c}22.7 \\
(22.32-23.08)\end{array}$ & \\
\hline Race & $\begin{array}{c}6.73 \\
(5.81-7.64)\end{array}$ & $\begin{array}{c}79.29 \\
(74.25-84.34)\end{array}$ \\
\hline Gender & $\begin{array}{c}6.33 \\
(5.71-6.95)\end{array}$ & $\begin{array}{c}66.83 \\
(62.13-71.53)\end{array}$ \\
\hline Age & $\begin{array}{c}6.19 \\
(5.66-6.71)\end{array}$ & $\begin{array}{c}70.03 \\
(65.57-74.49)\end{array}$ \\
\hline Weight & $\begin{array}{c}2.79 \\
(2.35-3.23)\end{array}$ & $\begin{array}{c}67.13 \\
(59.84-74.42)\end{array}$ \\
\hline Other Physical & $\begin{array}{c}4.15 \\
(3.59-4.70)\end{array}$ & $\begin{array}{c}79.01 \\
(74.45-83.57)\end{array}$ \\
\hline Religion & $\begin{array}{c}1.70 \\
(1.34-2.07)\end{array}$ & $\begin{array}{c}64.62 \\
(53.95-75.28)\end{array}$ \\
\hline Physical Disability & $\begin{array}{c}1.15 \\
(.85-1.45)\end{array}$ & $\begin{array}{c}71.08 \\
(60.13-82.03)\end{array}$ \\
\hline Income & $\begin{array}{c}1.61 \\
(1.29-1.94)\end{array}$ & $\begin{array}{c}64.43 \\
(55.30-73.56)\end{array}$ \\
\hline Mental Health & $\begin{array}{c}.99 \\
(.74-1.25)\end{array}$ & $\begin{array}{c}68.43 \\
(54.38-82.47)\end{array}$ \\
\hline Sexual Orientation & $\begin{array}{c}.58 \\
(.36-.79)\end{array}$ & $\begin{array}{c}48.53 \\
(30.58-66.47)\end{array}$ \\
\hline
\end{tabular}

Notes: CCHS RRM, 2013, Respondents aged 25+; $\mathrm{N}=16,049$; Weighted results shown.

Approximately $23 \%$ of Canadians report having experienced at least one form of everyday discrimination in their lifetime and give at least one reason for the experience. Types of discrimination are grouped according to prevalence in Table 2. The most common types of discrimination reported by Canadians are in the first group - racial discrimination (6.73\%), gender discrimination (6.33\%) and age discrimination (6.19\%). The next group contains the next two most common types of discrimination reported by Canadians - discrimination for 'other physical characteristics' (at $4.15 \%$ ) and weight discrimination (2.79\%). The next group contains the next three most common reasons for discrimination - religion $(1.7 \%)$, income (1.61\%), and physical disability (1.15\%). Finally, the last group contains the least common types of discrimination reported by Canadians - discrimination for mental health reasons $(.99 \%)$ and due to sexual orientation $(.58 \%)$. 
The third column of Table 2 shows the percentage of people who listed each type of discrimination as the 'only' or 'main' form they experienced. This column illustrates that $79 \%$ of those who report experiencing racial discrimination, for example, experienced it as either the only or the main form of discrimination. By contrast, only approximately $65 \%$ of those who report experiencing gender, religious or income discrimination experienced those as the main or only forms of discrimination. These figures suggest that many Canadians report experiencing more than one form of discrimination.

Table 3 illustrates how types of self-reported experiences of discrimination overlap in Canada. This table shows the most common secondary types of discrimination experienced by people reporting each main type of discrimination. Due to Statistics Canada regulations surrounding the confidentiality of the CCHS RRM data, and the small sample size of the groups experiencing each type of discrimination, I am only able to report on the patterning of secondary types of discrimination that occur to at least $5 \%$ of the sample experiencing each main type of discrimination.

Table 3: Overlapping types of discrimination

\begin{tabular}{|c|c|}
\hline MAIN type of discrimination & Percent who also experienced \\
\hline \multirow[t]{2}{*}{ Race } & Gender (11\%) \\
\hline & Age (7\%) \\
\hline \multirow[t]{2}{*}{ Gender } & Age (14\%) \\
\hline & Weight (5\%) \\
\hline Age & Gender (10\%) \\
\hline \multirow[t]{3}{*}{ Weight } & Gender (9\%) \\
\hline & Age $(8 \%)$ \\
\hline & Other physical (7\%) \\
\hline \multirow[t]{2}{*}{ Religion } & Race (24\%) \\
\hline & Gender (6\%) \\
\hline Physical Disability & Age (13\%) \\
\hline \multirow[t]{2}{*}{ Other Physical } & Gender (6\%) \\
\hline & Age $(7 \%)$ \\
\hline Income & Gender (16\%) \\
\hline \multirow[t]{4}{*}{ Mental Health } & Age (10\%) \\
\hline & Weight (8\%) \\
\hline & Physical Disability (7\%) \\
\hline & Income (6\%) \\
\hline Sexual Orientation & None \\
\hline
\end{tabular}


Gender, age, and weight discrimination appear most frequently as secondary types of discrimination. For example, gender is mentioned as another reason for discrimination by $11 \%$ of those who report race discrimination as their main type of discrimination, $10 \%$ of those who report age as the main type, $9 \%$ of those who report weight as the main type, $6 \%$ of those who report religion as the main type, $6 \%$ of those who report other physical as the main type, and $16 \%$ of those who report income as the main type. Weight comes up as a secondary form of discrimination for $5 \%$ of those who report gender discrimination as the main type, and $8 \%$ of those who report discrimination for mental health issues as the main type.

Having established the overall prevalence of different types of discrimination in Canada, I move on to address the second research question: Who is most likely to experience each of the different types of everyday discrimination? Table 4 contains the results of logistic regression models predicting each of the different types of discrimination. Results for the model for discrimination due to sexual orientation, based on a smaller sample, are contained separately in Table 5. Table 6 expands on the models of experiences of racial and religious discrimination in Table 4 by including detailed information on respondents' racial and ethnic identity as independent variables. 


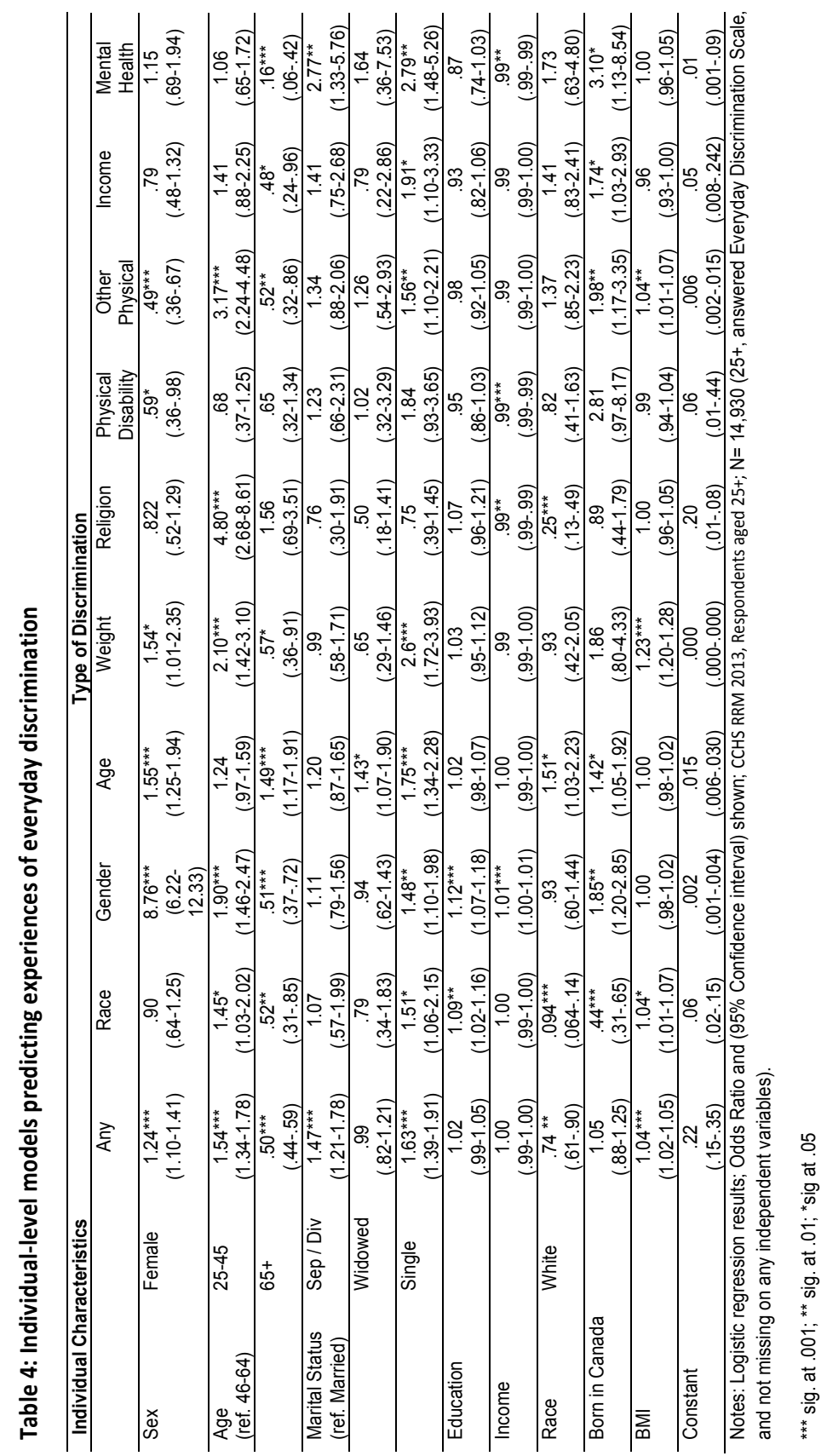


The third column of Table 4 illustrates the joint effect of all of the independent variables on the likelihood of reporting having experienced any type of discrimination in Canada. Controlling for education and income and whether a respondent was born in Canada, sex, age, marital status, race and BMI all have an impact on the likelihood of reporting experiences of discrimination. Women are $24 \%$ more likely to report experiencing discrimination than men. The younger cohort is $54 \%$ more likely and the older cohort is half as likely to report experiencing discrimination compared to those aged 45-64. Those who are separated or divorced are $47 \%$ more likely, and those who are single are $63 \%$ more likely to report experiencing discrimination than those who are married. Whites are $26 \%$ less likely to report experiencing discrimination than those in other racial / ethnic groups. Each one-point increase in BMI leads to a 4\% higher likelihood of reporting having experienced any form of discrimination, net of all other variables.

Examining the individual predictors of each type of discrimination, I first focus on gender. Table 4 shows that women are more likely to report experiencing gender, age and weight discrimination than men (net of all the other independent variables in the models). Controlling for the other variables, women are 8.76 times more likely to report experiences of gender discrimination than men. Men are almost twice as likely to report experiences of discrimination based on physical disability or other physical characteristics than women, net of other variables.

Age affects the likelihood of reporting experiencing every type of discrimination except discrimination based on physical disability. Those aged 65 and above are 50\% more likely to report experiencing age discrimination but are approximately half as likely to report experiencing racial, gender, weight, other physical and income discrimination, compared to those aged 46-64, controlling for other variables. Those aged 25-45 are twice as likely to report gender and weight discrimination, three times as likely to report discrimination based on other physical characteristics, and almost five times as likely to report religious discrimination compared to those aged 46-64, controlling for the other independent variables.

Marital status also affects reports of experiences of almost every type of discrimination, net of other variables. Most noticeably, those who are single are more likely to report discrimination based on race, gender, age, weight, other physical characteristics, income and mental health issues than those who are married / cohabiting, net of other variables. Those who are widowed are more likely to report age discrimination than those who are married, and those who are divorced are more likely to report discrimination due to mental health issues than those who are married, controlling for other variables. 
Indicators of social class have mixed effects on the likelihood of reporting experiencing different types of discrimination. Education affects race and gender discrimination positively, with each extra year of education predicting approximately a 10\% increase in the likelihood of reporting experiencing racial or gender discrimination, net of other variables. Income has a slight positive effect on reports of gender discrimination and a slight negative effect on reports of religious, physical disability, and mental health discrimination, net of other variables.

Whites are significantly less likely than non-Whites to report experiencing racial or religious discrimination, net of other variables. However, Whites are more likely to report experiencing age discrimination. Those born in Canada are more likely to report gender, age, other physical, income and mental health discrimination, and less than half as likely to report racial discrimination, as those not born in Canada, net of other variables.

BMI has a positive effect on the likelihood of reporting experiencing discrimination based on race, weight, and other physical characteristics, net of other variables. Most noticeably, a one-point increase in BMI leads to a $23 \%$ higher chance of reporting having experienced weight discrimination, controlling for all other variables in the model.

The model for discrimination due to sexual orientation, based on the sub sample who were asked about their sexual orientation (25-59-year olds), is contained in Table 5, below.

\begin{tabular}{|c|c|c|}
\hline \multicolumn{2}{|c|}{ Individual Characteristics } & \multirow{2}{*}{$\begin{array}{c}\begin{array}{c}\text { Discrimination due to sexual } \\
\text { orientation }\end{array} \\
.26^{*} \\
(.08-87)\end{array}$} \\
\hline Sex & Female & \\
\hline Age & & $\begin{array}{c}.98 \\
(.94-1.02)\end{array}$ \\
\hline \multirow[t]{3}{*}{$\begin{array}{l}\text { Marital Status } \\
\text { (ref. Married) }\end{array}$} & Sep / Div & $\begin{array}{c}.42 \\
(.042-4.10)\end{array}$ \\
\hline & Widowed & $\begin{array}{c}2.70 \\
(.36-20.35)\end{array}$ \\
\hline & Single & $\begin{array}{c}1.03 \\
(.34-3.13)\end{array}$ \\
\hline \multicolumn{2}{|l|}{ Education } & $\begin{array}{c}.92 \\
(.75-1.14)\end{array}$ \\
\hline \multicolumn{2}{|l|}{ Income } & $\begin{array}{c}1.00 \\
(.99-1.00)\end{array}$ \\
\hline Race & White & $\begin{array}{c}.87 \\
(.21-3.63)\end{array}$ \\
\hline \multicolumn{2}{|l|}{ Born in Canada } & $\begin{array}{c}.87 \\
(.22-3.43)\end{array}$ \\
\hline \multicolumn{2}{|l|}{ BMI } & $\begin{array}{c}.94 \\
(.86-1.03)\end{array}$ \\
\hline Sexuality & LGB & $\begin{array}{c}215.51^{* * *} \\
(65.76-706.30)\end{array}$ \\
\hline \multicolumn{2}{|l|}{ Constant } & $\begin{array}{c}.05 \\
(.002-1.37)\end{array}$ \\
\hline \multicolumn{3}{|c|}{$\begin{array}{l}\text { Notes: Logistic regression results; Odds Ratio and ( } 95 \% \text { Confidence interval) shown; CCHS RRM 2013, Respondents } \\
\text { aged 25-59; } N=11,234 \text { (answered Everyday Discrimination Scale, and not missing on any independent variables); Age } \\
\text { used as a continuous variable as sample is } 25-59 \text {. }\end{array}$} \\
\hline
\end{tabular}


The only variables which predict experiences of discrimination based on sexual orientation are sex and sexuality. Men are $75 \%$ more likely than women to report experiencing discrimination due to their sexual orientation, and those who identify as lesbian, gay, bisexual or transgender are 215 times more likely to report experiences of discrimination based on sexual orientation than those who are heterosexual, net of other variables.

\begin{tabular}{|c|c|c|c|}
\hline \multirow{2}{*}{\multicolumn{2}{|c|}{ Individual Characteristics }} & \multicolumn{2}{|c|}{ Type of Discrimination } \\
\hline & & Race & Religion \\
\hline Sex & Female & $\begin{array}{c}.89 \\
(.63-1.23) \\
\end{array}$ & $\begin{array}{c}.84 \\
(.52-1.36) \\
\end{array}$ \\
\hline \multirow[t]{2}{*}{$\begin{array}{l}\text { Age } \\
\text { (ref. 46-64) }\end{array}$} & $25-45$ & $\begin{array}{c}1.55^{*} \\
(1.10-2.17)\end{array}$ & $\begin{array}{c}4.35^{* * *} \\
(2.43-7.76)\end{array}$ \\
\hline & $65+$ & $\begin{array}{c}.52^{* *} \\
(.31-.86)\end{array}$ & $\begin{array}{c}1.44 \\
(.64-3.21) \\
\end{array}$ \\
\hline \multirow[t]{3}{*}{$\begin{array}{l}\text { Marital Status } \\
\text { (ref. Married) }\end{array}$} & Sep / Div & $\begin{array}{c}1.00 \\
(.55-1.82)\end{array}$ & $\begin{array}{c}.75 \\
(.30-1.89)\end{array}$ \\
\hline & Widowed & $\begin{array}{c}.84 \\
(.36-1.91) \\
\end{array}$ & $\begin{array}{c}.49 \\
(.18-1.36) \\
\end{array}$ \\
\hline & Single & $\begin{array}{c}1.46^{*} \\
(1.02-2.08)\end{array}$ & $\begin{array}{c}.79 \\
(.40-1.58)\end{array}$ \\
\hline \multicolumn{2}{|l|}{ Education } & $\begin{array}{c}1.09^{* *} \\
(1.02-1.16)\end{array}$ & $\begin{array}{c}1.09 \\
(.96-1.22)\end{array}$ \\
\hline \multicolumn{2}{|l|}{ Income } & $\begin{array}{c}1.00 \\
(.99-1.00)\end{array}$ & $\begin{array}{c}.99^{* *} \\
(.99-.99)\end{array}$ \\
\hline \multirow[t]{8}{*}{ Race (ref. = White) } & Aboriginal & $\begin{array}{c}11.35^{* * *} \\
(7.39-17.42)\end{array}$ & $\begin{array}{c}4.52^{* * *} \\
(1.71-11.95)\end{array}$ \\
\hline & Black & $\begin{array}{c}15.70^{* * *} \\
(7.92-31.11)\end{array}$ & $\begin{array}{c}3.58 \\
(.73-17.64)\end{array}$ \\
\hline & Asian & $\begin{array}{c}13.04^{* \star *} \\
(7.26-23.44)\end{array}$ & $\begin{array}{c}.57 \\
(.02-15.80)\end{array}$ \\
\hline & SW Asian & $\begin{array}{c}7.45^{* * *} \\
(4.07-13.64)\end{array}$ & $\begin{array}{c}5.81^{* * *} \\
(2.07-16.29)\end{array}$ \\
\hline & Arab & $\begin{array}{c}4.35^{* * *} \\
(1.66-11.40)\end{array}$ & $\begin{array}{c}6.75^{* * *} \\
(2.00-22.73)\end{array}$ \\
\hline & Latin & $\begin{array}{c}7.73^{* * *} \\
(3.51-17.05)\end{array}$ & $\begin{array}{c}.13^{* *} \\
(.03-.54)\end{array}$ \\
\hline & Other & $\begin{array}{c}5.86^{* *} \\
(1.42-24.26)\end{array}$ & $\begin{array}{c}12.73^{* * *} \\
(3.72-43.52)\end{array}$ \\
\hline & Multiple & $\begin{array}{c}10.74^{* * *} \\
(4.86-23.72)\end{array}$ & $\begin{array}{c}4.45 \\
(.21-95.66)\end{array}$ \\
\hline \multicolumn{2}{|l|}{ Born in Canada } & $\begin{array}{c}.42^{* * *} \\
(.26-.68) \\
\end{array}$ & $\begin{array}{c}.75 \\
(.33-1.73) \\
\end{array}$ \\
\hline \multicolumn{2}{|l|}{ BMI } & $\begin{array}{c}1.04^{* *} \\
(1.01-1.08)\end{array}$ & $\begin{array}{c}.99 \\
(.95-1.04)\end{array}$ \\
\hline \multicolumn{2}{|l|}{ Constant } & $\begin{array}{c}.005 \\
(.002-.015)\end{array}$ & $\begin{array}{c}.008 \\
(.002-.037)\end{array}$ \\
\hline \multicolumn{4}{|c|}{$\begin{array}{l}\text { Notes: Logistic regression results; Odds Ratio and (95\% Confidence interval) shown; CCHS RRM 2013, Respondents aged 25+; N= } \\
14,930 \text { ( } 25+\text {, answered Everyday Discrimination Scale, and not missing on any independent variables). }\end{array}$} \\
\hline
\end{tabular}

The models in Table 6 allow us to examine the effects of respondents' specific ethnic / racial identification on the likelihood of experiencing racial and religious discrimination. Net of the other independent variables, Blacks are 15.7 times as likely, Asians are 13 times as likely, and Aboriginals are 11.35 times as likely as Whites to report experiences of racial discrimination. Those identifying with multiple races are 10.74 times more likely to report experiences of racial discrimination as Whites. South and West Asians and Latinos are each 7.5 times as likely to report 
experiences of racial discrimination, compared to Whites. Those identifying as 'other' race are almost 6 times as likely, and Arabs are 4.35 times as likely to report experiences of racial discrimination compared to Whites, controlling for the other variables.

Those identifying as 'other' race are 12.73 times more likely to report experiencing religious discrimination than Whites, net of the other independent variables. Arabs are 6.75 times more likely and South and West Asians are 5.81 times more likely to report experiencing religious discrimination than Whites. Aboriginals are 4.52 times more likely to report experiencing religious discrimination compared to Whites, controlling for other variables in the model. Table 6 shows that the effects of the other independent variables (age, marital status, education, income, place of birth and BMI) on the likelihood of reporting experiencing racial and religious discrimination remain the same as they did in Table 4.

\section{Discussion}

Almost twenty-three percent of Canadians reported having experienced at least one form of everyday discrimination in their lifetime in the 2013 CCHS data. The most common types of self-reported discrimination are gender, age, and race, each reported by over six percent of the Canadian population. Discrimination based on physical characteristics is the next most common type, with almost three percent of Canadians reporting experiencing weight discrimination and over four percent reporting experiencing discrimination based on some other physical characteristic.

Experiences of discrimination due to religion, income, physical disability, mental health issues, and sexual orientation are less common, each reported by just under one to one and a half percent of the Canadian population. Some of these minority statuses apply to a much smaller number of people, though, thus overall population prevalence of these types of discrimination would be expected to be lower.

As outlined in the literature review, there is little previous research with which to compare these findings. Using DuMont and Forte's 2016 study, based on the 2009 GSS, we can see that almost all of the 2013 CCHS estimates of experiences of discrimination are higher than the estimates derived from the 2009 GSS (DuMont \& Forte 2016). However, it must be noted first that the GSS question only asked about experiences that occurred during the past five years, and second that the GSS contained different response categories for the reasons for discrimination.

Comparisons can be made most easily with regard to sex, age, physical disability, and sexual orientation. The GSS estimates show $4.7 \%$ 
reporting discrimination due to "sex," while the CCHS shows $6.33 \%$ reporting discrimination due to "gender". The GSS estimates show 3.3\% reporting discrimination due to "age," with the CCHS estimates showing $6.19 \%$ reporting discrimination due to "age." The GSS shows 1.1\% reporting discrimination due to "disability" while the CCHS reports $1.15 \%$ reporting discrimination due to "physical disability". The GSS reports $1 \%$ reporting discrimination due to "sexual orientation" while the CCHS reports only $.58 \%$ reporting discrimination due to "sexual orientation" (although the question was asked of a smaller age group in the CCHS, 25-59).

Other comparisons are more difficult. The GSS estimates showed that $5.4 \%$ reported experiencing discrimination due to "ethnicity and culture" and 5.1\% reported discrimination due to "race and colour", with $3.0 \%$ reporting discrimination due to language, and $2.5 \%$ reporting discrimination due to religion. The CCHS estimates that most closely reflect these categories show that $6.73 \%$ report experiencing discrimination due to "race" with $1.7 \%$ reporting discrimination due to "religion". The GSS reports 3.9\% reporting discrimination due to "physical appearance" while the CCHS reports $2.79 \%$ experiencing discrimination due to "weight," and $4.15 \%$ due to "other physical appearance". Discrimination due to income and mental health was not asked in the GSS. (DuMont \& Forte 2016).

These findings suggest that various forms of discrimination are encountered by Canadians in daily interpersonal interactions, most frequently discrimination by sex, age and race. However, we cannot say conclusively whether these experiences (or the self-reporting of these experiences) have increased over time. I suggest that the EDS (with comparable, if not exactly the same, categories of discrimination) be repeated on a regular basis within a nationally representative survey so that we can begin tracking historical changes in patterns of everyday discrimination in Canada.

Results also demonstrate that Canadians frequently report experiencing more than one form of discrimination, with discrimination due to gender, age and weight being the most common secondary forms of discrimination reported. Scholars have suggested that countries need to develop a comprehensive policy to address individuals being discriminated against on multiple grounds at the same time (Onufrio 2013). Canada would be well-placed to lead the way with such legislation.

Results from the individual-level models illustrate some predictable patterns. Not surprisingly, women are more likely to report experiences of gender discrimination than men, older adults are more likely to report experiences of age discrimination than younger adults, and non-Whites 
are more likely to report experiences of both racial and religious discrimination than Whites. Those born in Canada are less likely to report experiences of racial discrimination than those not born in Canada.

Further individual-level results highlight some more interesting patterns. Canadian women are more likely to report experiencing discrimination based on age and weight than men, while Canadian men are more likely to report experiencing discrimination based on physical disability and other physical characteristics than women. These findings may reflect entrenched stereotypes and gendered standards of beauty, where women are valued for being young and slender, and men are valued for being strong, muscular and tall (Clarke 2001; Godley \& McLaren 2010).

BMI is positively related to self-reports of discrimination not just based on weight but also based on race and other physical characteristics. Researchers in many countries have shown the negative consequences of weight discrimination across multiple social categories (Spahlholz et al. 2016). Weight discrimination is becoming a legal issue around the world, but weight is not yet a protected legal status in Canada. These results suggest that weight bias may be implicated in more than just weight discrimination in Canada and needs to be addressed at the societal level (Canadian Obesity Network 2016). Several countries, including Canada, have proposed potential policies and laws to prohibit weight discrimination, with strong public support (Puhl et al. 2015).

The effect of age on patterns of discrimination is interesting, with the younger cohort (25-45) more likely, and the older cohort (65 plus) less likely to report experiencing discrimination based on race, gender, weight, and other physical characteristics than the middle-aged cohort (46-64). The younger cohort is also more likely to report experiencing religious discrimination. These findings may reflect either a historic trend of increased awareness of the types of discrimination across the cohorts (Dewing 2013), or an increased propensity for younger cohorts to report negative experiences (Twenge 2014).

As suggested in the literature review, self-reports must be interpreted within the historical context during which the survey was administered. Over the past twenty years, there has been an increased awareness of, and education surrounding racism and sexism in Canadian society (Satzewich 2010). Thus, younger people in 2013 may have been both more aware of and more likely to report instances of perceived discrimination than older people. I suggest that the current social movements such as \#MeToo and Black Lives Matter, as well as the publicity surrounding the outcomes of the Truth and Reconciliation Commission, have further heightened youth's awareness of and sensitivity to unfair treatment 
based on marginalized statuses since 2013. It would be interesting to see if the age differences noticed in the 2013 data are even larger in 2018.

The inclusion of marital status in the individual-level models revealed some interesting patterns. Controlling for all other variables, single people were more likely to report experiencing discrimination due to gender, race, age, weight, other physical characteristics, income and mental health issues than married people. Recent research in psychology suggests that single people suffer from discrimination in many societies (Greitemeyer 2008). Since the EDS does not ask about discrimination based on marital status, single people who are feeling that they are discriminated against because of their marital status may be perceiving and reporting other types of discrimination instead (DePaulo \& Morris 2005).

The results concerning the impact of racial and ethnic identity on experiences of racial and religious discrimination are illuminating with regards to Canada's multicultural landscape. While all minority groups are more likely to experience racial discrimination than Whites, Blacks, Asians, and Aboriginals are the most likely to report racial discrimination, followed by those who identify with multiple racial groups. These results confirm the well-documented persistence of racism against Blacks and Aboriginals in Canada (Madibbo 2005; Mensah 2002; Paradies 2016).

Arabs and South and West Asians are more likely to report experiences of religious discrimination than Whites, which may be due to rising anti-Muslim sentiment, partially fueled by the international news media (Al-Solaylee 2017). Aboriginals are also more likely to report religious discrimination than Whites, further confirming the lasting effects of the colonial legacy of racism and cultural destruction on Aboriginals in Canada (Paradies 2016).

Individual-level models did not include controls for mental illness or physical disability, thus we cannot estimate the effects of those specific statuses on experiences of discrimination. However, we do have information on sexual orientation for a sub sample of respondents. Those who identify as lesbian, gay, or bisexual are a shocking 215 times more likely to report experiencing discrimination due to their sexual orientation than heterosexuals. Men are also more likely than women to report experiencing discrimination based on sexual orientation. Together, these findings suggest that gay and bisexual men are still particular targets for everyday discrimination in Canada, replicating findings of previous Canadian studies (Jewell \& Morrison 2010). 


\section{LiMitaTiONS}

As with all quantitative studies of discrimination, this study is limited by the survey questions asked. This paper relies on self reports of everyday experiences of discrimination. As with all self-reported measures, there may be unmeasured individual-level factors (depression, for example) which vary across groups and which account for higher perceptions of discrimination by certain groups. As stated earlier, the EDS may suffer from both minimization and vigilance biases (Kaiser \& Major 2006).

Additionally, the version of the EDS used in the CCHS only allows for the construction of variables that measure 'have you ever experienced discrimination due to ...' I am not able to construct measures of the frequency of different types of discrimination. Nor am I able to examine reasons for discrimination not included in the survey. Future quantitative work on discrimination in Canada should also examine 'major incidents' of discrimination. Future work using self-reported measures should include frequency measures and could benefit from a more detailed list of reasons for discrimination (including marital status, for example).

Descriptive results suggest that individuals report experiencing overlapping types of discrimination is present in Canada, yet the small sample size prohibits me from modeling the individual determinants of overlapping forms of discrimination. Future work with a larger sample could look at combinations of experiences of discrimination more deeply, as well as examining the interactive effect of individual level variables on multiple experiences of discrimination.

We must also remember that the CCHS excludes individuals living on Indian Reserves or other Aboriginal settlements, institutional residents, full-time members of the Canadian Armed Forces, residents of some remote regions, and those living in two Quebec health regions. While these exclusions only represent $3 \%$ of the national population, they may include individuals who are disproportionately likely to experience and / or report incidents of everyday discrimination.

Finally, this study does not examine the effect of discrimination on any outcome variables. Planned future work using the 2013 CCHS RRM will examine the relationship between experiences of discrimination and health outcomes in Canada.

\section{Conclusions}

This work provides baseline descriptive statistics on the prevalence and patterns of self-reported everyday discrimination in Canada in the ear- 
ly twenty first century. Almost $23 \%$ of Canadians report experiencing discrimination routinely, with age, sex and racial discrimination experienced most frequently. Sexism, racism, and ageism all still need to be addressed in Canadian society.

Sex, age, marital status, race, place of birth, and BMI all contribute to individuals' reported experiences of discrimination. Gay men are particularly at risk for experiencing discrimination based on sexual orientation; Blacks, Asians, and Aboriginals are particularly at risk for experiencing racial discrimination; and Arabs, South and West Asians, and Aboriginals are particularly at risk for experiencing religious discrimination.

There is strong evidence of the persistence of self-reported everyday discrimination in Canada, despite over thirty years of federal human rights legislation. While legislation covers more egregious instances of discrimination such as hate crimes, hate speech, and discriminatory employment practices, it is difficult to legislate against the subtler forms of discrimination reported on in the EDS. I suggest that what is needed is education and awareness campaigns. Such campaigns should address each type of discrimination separately, as the individual-level determinants of discrimination depend on the type of discrimination experienced (Nakhaie et al. 2016). Campaigns need to address both the causes and the consequences of discrimination at the interpersonal level, including education and awareness for both perpetrators and victims.

Interventions to reduce everyday discrimination need to occur at multiple levels, including the individual, community, and policy-level (Lewis et al. 2015). Individual-level interventions with victims of discrimination might include programs such as value affirmation, promoting resilience to discrimination, and forgiveness. Individual-level interventions with perpetrators might include programs such as anti-racism education and implicit bias awareness training. At the community-level, interventions could include antiracism and anti weight bias social marketing and media campaigns.

In the conclusion to his seminal 1965 work, Porter wrote, "Canada... has a long way to go to become in any sense a thorough-going democracy" (Porter 1965: 557). A 'thorough-going democracy' would suggest a society where citizens are free from the threat of experiencing discrimination due to their social status. Fifty years later, we still have a long way to go to ensure that marginalized groups are protected from everyday experiences of discrimination. 


\section{REFERENCES}

Abada, T., Hou, F., \& Ram, B. 2009. Ethnic differences in educational attainment among the children of Canadian immigrants. Canadian Journal of Sociology, 34(1):1-28.

Al-Solaylee, K. 2017. "Anti-Muslim hate has been in Canada - and our politics - long before the violence." Editorial. The Globe and Mail, Jan. 31, 2017. Retrieved from: https://www.theglobeandmail.com/opinion/ in-the-culture-of-hate-toward-muslims-dont-forget-the-made-in-canadapolitical-contributions/article33847973/

Anderson, B. 2017. Sexual harassment of women is widespread in Canada. Abacus Data. (http://abacusdata.ca/sexual-harassment-of-women-is-widespread-in-canada/). Retrieved 22 February, 2018.

Beiser, M. \& Hou, F. 2016. Mental health effects of premigration trauma and postmigration discrimination on refugee youth in Canada. The Journal of Nervous and Mental Disease, 204(6):464-470. doi:10.1097/ NMD.0000000000000516

Beiser, M., Noh, S., \& Hou, F. 2001. Southeast Asian refugees' perceptions of racial discrimination in Canada. Canadian Ethnic Studies Journal, 33(1):46-62.

Berry, J.W., \& Hou, F. 2017. Acculturation, discrimination and wellbeing among second generation of immigrants in Canada. International Journal of Intercultural Relations, 61:29-39.

Browne, A.J. 2017. Moving beyond description: Closing the health equity gap by redressing racism impacting Indigenous populations. Social Science and Medicine, 184:23-26. doi: 10.1016/j.socscimed.2017.04.045

Canadian Obesity Network. 2016. EveryBODY Matters. Report prepared for the $3^{\text {rd }}$ Canadian Weight Bias Summit, May 26-27, 2016. Edmonton. Retrieved from: http://www.obesitynetwork.ca/files/3rd Weight Bias Summit_Full_Report_.pdf

Cary, L.A., Chasteen, A.L., \& Remedios, J. 2017. The ambivalent ageism scale: Developing and validating a scale to measure benevolent and hostile ageism. Gerontologist, 57(2): e27-e36. Doi: 10.1093/geront/gnw118.

Chen, D., \& Yang, T.-C. 2014. The pathways from perceived discrimination to self-rated health: An investigation of the roles of distrust, social capital, and health behaviours. Social Science and Medicine, 104:64-73. DOI: 10.1016/j.socscimed.2013.12.021

Chen, W., Myles, J., \& Picot, G. 2012. Why have poorer neighbourhoods stagnated economically while the richer have flourished? Neighbourhood income inequality in Canadian cities. Urban Studies, 49 (4): 877-896.

Clarke, L.H. 2001. Older Women's Bodies and the Self: The Construction of Identity in Later Life. Canadian Review of Sociology and Anthropology, 38:441-64. 
DePaulo, B.M. \& Morris, W.L. 2005. Singles in Society and Science. Psychological Inquiry, 16, (2-3):57-83. doi:10.1080/1047840X.2005.9682918

Dewing, M. 2013. Canadian Multiculturalism. Background Paper. Ottawa: Library of Parliament. Retrieved from: https://bdp.parl.ca/Content/LOP/ ResearchPublications/2009-20-e.pdf

Driedger, L. \& Mezoff, R.A. 1981. Ethnic prejudice and discrimination in Winnipeg high schools. Canadian Journal of Sociology, 6(1):1-17.

Du Mont, J. \& Forte, T. 2016. Perceived discrimination and self-rated health in Canada: An exploratory study. BMC Public Health, 16:742-751. doi:10.1186/s12889-016-3344-y

Fleras, A. 2014. Racisms in Multicultural Canada: Paradoxes, Politics, and Resistance. Waterloo, ON: Wilfred Laurier University Press.

Fleras, A. 2016. Theorizing micro-aggressions as racism 3.0: shifting the discourse. Canadian Ethnic Studies Journal, 48(2).

Galabuzi, G.-E. 2010. Measuring racial discrimination in Canada: A call for context and more inclusive approaches. Canadian Journal for Social Research, 3(2):24-44.

Gayman, M.D. \& Barragan, J. 2013. Multiple perceived reasons for major discrimination and depression. Society and Mental Health, 3(3): 203-220. doi: $10.1177 / 2156869313496438$

Giroux, H.A. 2017. White nationalism, armed culture and state violence in the age of Donald Trump. Philosophy and Social Criticism: 1-24. doi: $10.1177 / 0191453717702800$

Greitemeyer, T. 2008. Stereotypes of singles: Are singles what we think? European Journal of Social Psychology, 39:368-33. Doi: 10.1002/ejsp.542

Guppy, N. \& Luongo, N. 2015. The rise and stall of Canada's gender-equity revolution. Canadian Review of Sociology, 52(3):241-265.

Hankivsky O. \& Christofferson A. 2008. Intersectionality and the determinants of health: a Canadian perspective. Critical Public Health, 18: 271-283. doi:10.1080/09581590802294296

Jedwab, J. 2014. The Multicultural Question: Debating Identity in $21^{\text {st }}$ Century Canada. Montreal: McGill-Queens University Press.

Jedwab, J. \& Satzewich, V. 2015. "Introductory Essay: John Porter's The Vertical Mosaic, 50 Years Later." In Porter, J. The Vertical Mosaic: An analysis of social class and power in Canada, 50 th Anniversary Edition. Toronto: University of Toronto Press: pp. xxvii-xxxvii.

Jewell, L.M. \& Morrison, M.A. 2010. But There's a Million Jokes About Everybody ...": Prevalence of, and Reasons for, Directing Negative Behaviors Toward Gay Men on a Canadian University Campus. Journal of Interpersonal Violence, 25(11). doi: 10.1177/0886260509354499 
John, U., Hanke, M., Grothues, J., \& Thyrian, J.R. 2006. Validity of Overweight and Obesity in a Nation Based on Self-Report Versus Measurement Device Data. European Journal of Clinical Nutrition, 60:372-77.

Kaiser, C.R. \& Major, B. 2006. A social psychological perspective on perceiving and reporting discrimination. Law and Social Inquiry, 31(4):801-830.

Kim, G., Sellbom, M., \& Ford, K-L. 2014. Race/ Ethnicity and measurement equivalence of the everyday discrimination scale. Psychological Assessment, 26(3): 892-900. doi:10.1037/a0036431

Kim, I. \& Noh, S. 2016. Racial/ethnic variations in the main and buffering effects of ethnic and nonethnic supports on depressive symptoms among five ethnic immigrant groups in Toronto. Ethnicity \& Health, 21(3): 215232. doi:10.1080/13557858.2015.1061101

Kymlicka, W. 2004. Marketing Canadian pluralism in the international arena. International Journal, 59(4): 829-852. http://journals.sagepub.com/doi/ pdf/10.1177/002070200405900407

Leber, B. 2017. Police-reported hate crime in Canada, 2015. Juristat, Statistics Canada Publication 85-002-X. http://www.statcan.gc.ca/pub/85002-x/2017001/article/14832-eng.htm

Lewis, T.T., Cogburn, C.D., \& Williams, D.R. 2015. Self-reported experiences of discrimination and health: Scientific advances, ongoing controversies, and emerging issues. Annual Review of Clinical Psychology, 11: 407440. doi:10.1146/annurev-clinpsy-032814-112728

Lightman, N. \& Gingrich, L.G. 2012. The intersecting dynamics of social exclusion: age, gender, race and immigrant status in Canada's labour market. Canadian Ethnic Studies, 44(3): 121-145. doi://10.1353/ces.2013.0010

Litchmore, R.V.H. \& Safdar, S. 2015. Perceptions of discrimination as a marker of integration among Muslim-Canadians: The role of religiosity, ethnic identity, and gender. International Migration and Integration, 16:1872014. doi:10.1007/s12134-014-0337-5

Logie, C., James, L., Tharao, W., \& Loutfy, M. 2013. Associations between HIV-related stigma, racial discrimination, gender discrimination, and depression among HIV-positive African, Caribbean, and Black women in Ontario, Canada. AIDS Patient Care and STDs, 27(2): 114-122. doi:10.1089/apc.2012.0296

Madibbo, A. I. 2005. Immigration, race, and language: Black francophones of Ontario and the challenges of integration, racism, and language discrimination. CERIS Working Paper Series No. 38.

Mensah, J. 2002. Black Canadians: History, experiences, social conditions. Halifax, NS: Fernwood Publishing

Nagra, B. \& Maurutto, P. 2016. Crossing borders and managing racialized identities: Experiences of security and surveillance among young Canadian Muslims. Canadian Journal of Sociology, 41(2): 165-194. 
Nakhaie, R. \& Wijesingha, R. 2015. Discrimination and health of male and female Canadian immigrants. International Migration and Integration, 16: 1255-1272. doi:10.1007/s12134-014-0392-y

Ontario Human Rights Commission. 2001. An intersectional approach to discrimination: Addressing multiple grounds in human rights claims. Discussion paper. Retrieved from: http://www.ohrc.on.ca/en/intersectionalapproach-discrimination-addressing-multiple-grounds-human-rights$\underline{\text { claims }}$

Onufrio, M.V. 2013. Intersectional discrimination in the European legal systems: Toward a common solution? International Journal of Discrimination and the Law, 14(2): 126-140. doi:10.1177/1358229113514675

Pager, D. \& Shepherd, H. 2008. The sociology of discrimination: Racial discrimination in employment, housing, credit, and consumer markets. Annual Review of Sociology, 34:181-209

Paradies, Y. 2016. Colonisation, racism, and Indigenous health. Journal of Population Research, 33(1):83-97. Doi: 10.1007/s12546-01609159-y

Pascoe, E.A. \& Richman, L.S. 2009. Perceived discrimination and health: A meta-analytic review. Psychological Bulletin, 135(4): 531-554. doi:10.1037/ a0016059

Porter, John. 1965. The Vertical Mosaic: An analysis of social class and power in Canada. Toronto: University of Toronto Press.

Porter, John. 2015. The Vertical Mosaic: An analysis of social class and power in Canada, $50^{\text {th }}$ Anniversary Edition. Toronto: University of Toronto Press.

Puhl, R.M., Latner, J.D., O’Brien, K.S., Luedicke, J., Danielsdottir, S., \& Ramos Salas, X. 2015. Potential policies and laws to prohibit weight discrimination: Public views from four countries. Millbank Quarterly, 93(4):691731.

Ramraj, C., Shahidi, F.V., Darity, W., Kawachi, I., Zuberi, D., \& Siddiqi, A. 2016. Equally inequitable? A cross-national comparative study of racial health inequalities in the United States and Canada. Social Science and Medicine, 161:19-26. doi: 10.1016/j.socscimed.2016.05.028

Samuel, J. \& Verma, R.B.P. 2010. The development of benchmarks and indicators for compiling a report card on racism in Canada. Canadian Journal for Social Research, 3(2):3-23.

Satzewich, V. 2010. Measuring racism: A case for Verstehen. Canadian Journal for Social Research, 3(2):47-57.

Seng J.S., Lopez W.D., Sperlich M., Hamama L., \& Meldrum C.D.R. 2012. Marginalized identities, discrimination burden, and mental health: Empirical exploration of an interpersonal-level approach to modeling intersectionality. Social Science \& Medicine, 75:2437-2445. doi: 10.1016/j. socscimed.2012.09.023 
Siddiqi, A., Kawachi, I., Keating, D.P., \& Hertzman, C. 2013. A comparative study of population health in the United States and Canada during the neoliberal era, 1980-2008. International Journal of Health Services, 43(2): 193-216. doi: 10.2190/HS.43.2.b

Spahlholz, J., Baer, N., Konig, H.-H., Riedel-Heller, S.G., \& Luck-Sikorski, C. 2016. Obesity and discrimination - a systematic review and meta-analysis of observational studies. Obesity Review, 17:43-55.

Spence, N.D., Wells, S., Graham, K., \& George, J. 2016. Racial discrimination, cultural resilience, and stress. The Canadian Journal of Psychiatry, 61(5): 298-307. doi:10.1177/0706743716638653

Spencer, E.A., Appleby, P.N., Davey, G.K., \& Key, T.J. 2002. Validity of selfreported height and weight in 4808 EPIC-Oxford participants. Public Health Nutrition, 54:561-65.

Statistics Canada. 2016a. Release Note: Strengthening the evidence base on the social determinants of health: measuring everyday discrimination through a CCHS Rapid Response Module. Health Promotion and Chronic Disease Prevention in Canada, 36(2): 41.

Statistics Canada. 2016b. CCHS 201307-201310: Topical Index Master File Rapid Response - EDS. 15 pp. Retrieved from: http://www23.statcan. gc.ca/imdb/pIX.pl?Function=showStatic ArchiveHTML\&a $=1 \& \mathrm{fl}=\mathrm{ht}$ tp://www23.statcan.gc.ca/imdb-bmdi/document/3226_D80 T1-V1-eng. htm\&Item Id=149987

Statistics Canada. 2016c. Canadian Community Health Survey 2013 - Everyday Discrimination Scale Questionnaire. $100 \mathrm{pp}$. Retrieved from: http:// www23.statcan.gc.ca/imdb/pIX.pl?Function=showStaticArchiveHTM $\mathrm{L} \& \mathrm{a}=1 \& \mathrm{fl}=\mathrm{http}: / / \mathrm{www} 23$.statcan.gc.ca/imdb-bmdi/document/3226 D80 T1-V1-eng.htm\&Item Id=149987

Statistics Canada. 2016d. Canadian Community Health Survey (CCHS) Rapid response on the Everyday Discrimination Scale Complement to the User Guide. Retrieved from: http://www23.statcan.gc.ca/imdb/pIX.pl?Func $\underline{\text { tion=showStaticArchiveHTML\&a }=1 \& \mathrm{fl}=\mathrm{http}: / / \text { www23.statcan.gc.ca/ }}$ imdb-bmdi/document/3226_D80 T1-V1-eng.htm\&Item_Id=149987

Stucky, B.D., Gottfredson, N.C., Panter, A.T., Daye, C.E., Allen, W.R., \& Wightman, L.F. 2011. An item factor analysis and item response theory-based revision of the everyday discrimination scale. Cultural Diversity and Ethnic Minority Psychology, 17(2):175-185. doi:10.1037/a0023356

Twenge, J.M. 2014. Generation Me: Why Today's Young Americans Are MoreConfident, Assertive, Entitled-And More Miserable Than Ever Before. Second Edition. New York: Atria Books.

Veenstra, G. 2009. Racialized identity and health in Canada: Results from a nationally representative survey. Social Science and Medicine, 69:538-542. doi: 10.1016/j.socscimed.2009.06.009 
Veenstra, G. 2011. Race, gender, class, and sexual orientation: intersecting axes of inequality and self-rated health in Canada. International Journal for Equity in Health., 10(3):1-11. http://www.equityhealthj.com/con$\underline{\text { tent } / 10 / 1 / 3}$

Veenstra, G. 2013. The gendered nature of discriminatory experiences by race, class, and sexuality: A comparison of intersectionality theory and the subordinate male target hypothesis. Sex Roles, 68: 646-659. doi:10.1007/ s11199-012-0243-2

Veenstra, G. \& Patterson, A.C. 2016a. South Asian-White health inequalities in Canada: intersections with gender and immigrant status. Ethnicity and Health, 21(6): 639-648. doi:10.1080/13557858.2016.1179725

. 2016b. Black-White health inequalities in Canada. Journal of Immigrant and MinorityHealth, 18: 51-57. doi:10.1007/s10903-014-0140-6

Williams, C.C., Curling, D., Steele, L.S., Gibson, M.F., Daley, A., Green, D.C., \& Ross, L.E. 2017. Depression and discrimination in the lives of women, transgender and gender liminal people in Ontario, Canada. Health and Social Care in the Community, 25(3): 1139-1150. doi:10.1111/hsc.12414

Williams, D.R. 2016. Measuring Discrimination Resource. 24 pages. Retrieved from: https://scholar.harvard.edu/files/davidrwilliams/files/measuring discrimination resource june 2016.pdf

Williams, D.R., John, D.A., Oyserman, D., Sonnega, J., Mohammed, S.A., \& Jackson, J.S. 2012. Research on discrimination and health: An exploratory study of unresolved conceptual and measurement issues. American Journal of Public Health, 102(5): 975-978.

Williams, D.R. \& Mohammed, S.A. 2009. Discrimination and racial disparities in health: Evidence and needed research. Journal of Behavioral Medicine, 32(3):335-351.

2013. Racism and health I: Pathways and scientific evidence. American Behavioral Scientist, 57(8):1152-1173. doi:10.1177/0002764213487340

Williams, D.R., Yu, Y., Jackson, J.S., \& Anderson, N.B. 1997. Racial differences in physical and mental health: Socio-economic status, stress and discrimination. Journal of Health Psychology, 2(3):335-351.

Zerger, S., Bacon, S., Corneau, S., Skosireva, A., McKenzie, K., Gapka, S., O’Campo, P., Sarang, A., \& Stergiopoulos, V. 2014. Differential experiences of discrimination among ethnoracially diverse persons experiencing mental illness and homelessness. BMC Psychiatry, 14: 353-364. doi:10.1186/s12888-014-0353-1 


\section{ACKNOWLEDGEMENTS}

This research was supported by funds to the Canadian Research Data Centre Network (CRDCN) from the Social Sciences and Humanities Research Council (SSHRC), the Canadian Institute for Health Research (CIHR), the Canadian Foundation for Innovation (CFI), and Statistics Canada. Although the research and analysis are based on data from Statistics Canada, the opinions expressed do not represent the views of Statistics Canada. The author would like to thank her colleague, Dr. Ozouf Sénamin Amedegnato, Associate Professor in the School of Languages, Linguistics, Literatures and Culture at the University of Calgary, for providing the French translation.

Jenny Godley is an Associate Professor of Sociology at the University of Calgary. Trained as a quantitative sociologist and a demographer, her research focuses on understanding the mechanisms through which social class and other aspects of social inequality affect health. She is currently working on a project examining whether experiences of everyday discrimination, as described in this paper, account for some of the impact of social statuses on mental and physical health.

E-Mail:jgodley@ucalgary.ca 